\title{
Evaluation of familial aggregation, vegetable consumption, legumes consumption, and physical activity on functional constipation in families of children with functional constipation versus children without constipation
}

\author{
Seyed Mohsen Dehghani', Hossein Moravej ${ }^{2}$, Elahe Rajaei ${ }^{3}$, Hazhir Javaherizadeh ${ }^{1}$ \\ ${ }^{1}$ Gastroenterohepatology Research Center, Shiraz Transplant Research Center, Nemazee Teaching Hospital, Shiraz University \\ of Medical Sciences, Shiraz, Iran \\ 2Department of Pediatric Endocrinology, Nemazee Teaching Hospital, Shiraz University of Medical Sciences, Shiraz, Iran \\ ${ }^{3}$ Department of Paediatrics, Nemazee Teaching Hospital, Shiraz University of Medical Sciences, Shiraz, Iran
}

Prz Gastroenterol 2015; 10 (2): 89-93

DOI: $10.5114 /$ pg.2015.48996

Key words: functional constipation, physical activity, Rome III, vegetable consumption.

Address for correspondence: Dr. Hazhir Javaherizadeh, Gastroenterohepatology Research Center, Nemazee Teaching Hospital, Shiraz University of Medical Sciences, Shiraz, Iran, phone: +98 7136474298, e-mail: hazhirja@yahoo.com

\begin{abstract}
Introduction: Constipation is a frequent complication in paediatrics. Most of the constipation is functional. Functional constipation constitutes $25 \%$ of visits in paediatric gastroenterology clinics. Two studies were published regarding aggregation or clustering of functional constipation. Only one of these research projects was about a paediatric population.

Aim: To elucidate the cluster pattern of constipation among the families of children with constipation.

Material and methods: This case-control study was carried out on the families of 37 children $<18$ years old with chronic functional constipation and the families of 37 healthy children as controls. Cases were enrolled in the study according to Rome III criteria for constipation. The control group was selected from children < 18 years old who visited the well baby clinic of the university. Parents and siblings were evaluated regarding constipation. Rome II and III were used for evaluation of constipation for adults and children, respectively. Data was analysed using SPSS (Chicago, IL, USA). The $\chi^{2}$ and $t$-test were used for comparison.

Results: Physical activity and vegetable consumption were seen more frequently in the control group compared to the cases, but these differences were statistically insignificant. Constipation in mothers was significantly higher in the case group compared to the control group $(p=0.015)$. There was no significant difference between the two groups regarding exercise and vegetable consumption.

Conclusions: The frequency of constipation among mothers was significantly higher in the case group compared to the control group. Another study is recommended in a larger population for evaluation of genetic background, diet, physical activity, and familial clustering among mothers of children with constipation.
\end{abstract}

\section{Introduction}

Constipation is a frequent complication in paediatrics. Most of the constipation is functional. In other countries, the prevalence of constipation was reported at approximately $15.4-30 \%$. In a recent study, the prevalence of constipation was estimated at about $1.9-27.2 \%$ in the general population in the US [1]. Functional constipation constitutes $25 \%$ of visits in paediatric gastroenterology clinics [2].
Several studies have been published about familial clustering or aggregation of gastrointestinal problem [3]. Some evidence suggests that there is a cluster pattern in the families of children with constipation. Two studies were published regarding aggregation or clustering of functional constipation [4,5]. Only one of these publications was about a paediatric population [5]. A study by Chan et al. compared the families of persons with constipation with normal persons. They found sub- 
jects with more family having constipation will have higher risk of constipation compared to people with just one or two family members [4]. In the Borowitz et al. study, family history of constipation in parents or siblings of constipated children was similar to that of normal children [6]. These studies were carried out in the USA $[4,6]$. There has been no published research on familial clustering or aggregation of constipation in Asian countries.

\section{Aim}

The aim of this study was to find a cluster pattern of constipation among families of children with constipation versus families of normal children.

\section{Material and methods}

This case-control study was carried out on the families of 37 children with constipation as cases, and on the families of 37 healthy children without constipation as controls. The place of study was the Imam Reza clinic of Shiraz University of Medical Sciences. The children's families were evaluated regarding constipation. Each of the families were asked about physical activity of more than 20 min per day on at least 3 days per week, and vegetable and legumes consumption as serving per week. All children and their families had normal patterns of water drinking in their history.

Exclusion criteria for probands was age $<6$ months or age > 18 years; history of divorce or separation in family; and history of metabolic, organic, or endocrine disorder. Informed consent was signed by participants. Questionnaires were filled in by parents for siblings aged < 18 years and by siblings with age > 18 years.

Rome II criteria were used for defining constipation in adults. Rome II criteria are as follows: At least 12 weeks, which need not be consecutive, in the preceding 12 months of two or more of the following: (1) straining $>1 / 4$ of defecations; (2) lumpy or hard stools $>1 / 4$ of defecations; (3) sensation of incomplete evacuation > 1/4 of defecations; (4) sensation of anorectal obstruction/ blockage $>1 / 4$ of defecations; (5) manual manoeuvres to facilitate $>1 / 4$ of defecations (e.g., digital evacuation, support of the pelvic floor); and/or (6) < 3 defecations per week. Loose stools are not present, and there are insufficient criteria for irritable bowel syndrome (IBS).

Rome III criteria were used for the children with constipation. Rome III criteria are as follows: neonates and toddlers [7]: at least two of the following symptoms must occur for at least 1 month; < two defecations per week; > one episode per week of incontinence after the acquisition of toileting skills; history of excessive stool retention; history of painful or hard bowel move- ments; presence of a large faecal mass in the rectum, and history of large-diameter stools that may obstruct the toilet. Children and adolescents [8]: symptoms must occur at least once per week for at least 2 months and include 2 or more of the following in a child with a developmental age of $>4$ years with insufficient criteria of irritable bowel syndrome: two or fewer defections in the toilet per week; at least one episode of faecal incontinence per week; history of retentive posturing or excessive volitional stool retention; history of painful or hard bowel movements; presence of a large faecal mass in the rectum; history of large-diameter stools that may obstruct the toilet.

The sample size was calculated by Power SSC software $(\mathrm{a}=0.05$, Power $=95 \%, \mathrm{P}$ case $=38 \%, \mathrm{P}$ control $=$ $8 \%)$. For data collection, questionnaires were designed according to Rome III and Rome II criteria for children and adults, respectively.

\section{Statistical analysis}

Data was analysed using SPSS version 13.0 (Chicago, IL.,USA).

\section{Results}

Seventy-four parents were included in each group separately. The numbers of siblings were 21 and 23 for case and control groups, respectively. The total numbers of families in cases and controls were 95 and 97, respectively.

The sensation of incomplete evacuation for at least $25 \%$ of defecations was significantly more frequent in mothers of children with constipation compared to mothers of normal children $(p=0.001)$. There was no significant difference between fathers in the two groups regarding positive criteria for functional constipation. There was no significant difference between two groups regarding other criteria (Table I).

There was no significant difference between other children of families of case groups compared to control groups regarding criteria of constipation (Table II).

In the case group, 10 (27\%) of fathers had constipation versus 11 (29.7\%) fathers in the control group $(p=0.796)$. Of all mothers in the case group $18(48.6 \%)$ had constipation, which was significantly higher than the $8(21.6 \%)$ mothers in the control group $(p=0.015)$. There was no significant difference between the two groups regarding constipation in the first child (case $6(40 \%)$ vs. control 10 (55.6\%), $p=0.373$ ) (Table III).

Vegetable consumption was significantly higher among mothers of controls compared to the case group $(p=0.045)$. In total, vegetable consumption was significantly higher in the control families compared to case families. 
Table I. Frequency of criteria of constipation among parents of children with constipation compared to parents of normal children

\begin{tabular}{|c|c|c|c|c|c|c|}
\hline \multirow[t]{2}{*}{ Criteria } & \multicolumn{3}{|c|}{ Father } & \multicolumn{3}{|c|}{ Mother } \\
\hline & Case, $n(\%)$ & Control, $n(\%)$ & Value of $p$ & Case, $n(\%)$ & Control, $n(\%)$ & Value of $p$ \\
\hline $\begin{array}{l}\text { Lumpy or hard stool in at least } 25 \% \\
\text { of defecations }\end{array}$ & $14(37.8)$ & $17(45.9)$ & 0.48 & 19 (51.4) & $20(54.1)$ & 0.816 \\
\hline $\begin{array}{l}\text { Sensation of incomplete evacuation } \\
\text { for at least } 25 \% \text { of defecations }\end{array}$ & $10(27)$ & $13(35.1)$ & 0.451 & $18(48.6)$ & $5(13.5)$ & 0.001 \\
\hline $\begin{array}{l}\text { Sensation of anorectal obstruction/ } \\
\text { blockage for at least } 25 \% \text { of defecations }\end{array}$ & $9(24.3)$ & 8 (21.6) & 0.782 & $10(27)$ & $5(13.5)$ & 0.148 \\
\hline $\begin{array}{l}\text { Manual manoeuvre to facilitate at least } \\
25 \% \text { of defecations }\end{array}$ & $5(13.5)$ & $1(2.7)$ & 0.088 & $6(16.2)$ & $2(5.4)$ & 0.134 \\
\hline Fewer than 3 defecations per week & $4(10.8)$ & $1(2.7)$ & 0.165 & $4(10.8)$ & $2(5.4)$ & 0.394 \\
\hline
\end{tabular}

Table II. Frequency of criteria among other children of the probands' family compared to normal children's family

\begin{tabular}{lccccccccc}
\hline & \multicolumn{3}{c}{ Child 1 } & \multicolumn{3}{c}{ Child 2 } & & Child 3 \\
\cline { 2 - 10 } & $\begin{array}{l}\text { Case } \\
n(\%)\end{array}$ & $\begin{array}{c}\text { Control } \\
n(\%)\end{array}$ & $\begin{array}{c}\text { Value } \\
\text { of } p\end{array}$ & $\begin{array}{c}\text { Case } \\
n(\%)\end{array}$ & $\begin{array}{c}\text { Control } \\
n(\%)\end{array}$ & $\begin{array}{c}\text { Value } \\
\text { of } p\end{array}$ & $\begin{array}{c}\text { Case } \\
n(\%)\end{array}$ & $\begin{array}{c}\text { Control } \\
n(\%)\end{array}$ & $\begin{array}{c}\text { Value } \\
\text { of } p\end{array}$ \\
\hline $\begin{array}{l}\text { Number of defecations per } \\
\text { week }\end{array}$ & $3(20)$ & $5(27.8)$ & 0.604 & $1(25)$ & $0(0)$ & 0.285 & $1(50)$ & $0(0)$ & 0.386 \\
\hline $\begin{array}{l}\text { Positive history of faecal } \\
\text { soiling }\end{array}$ & $3(20)$ & $6(33.3)$ & 0.392 & $1(25)$ & $0(0)$ & 0.285 & $1(50)$ & $0(0)$ & 0.386 \\
\hline $\begin{array}{l}\text { History of large diameter } \\
\text { faeces }\end{array}$ & $5(33.3)$ & $6(33.3)$ & 1 & $1(25)$ & $0(0)$ & 0.285 & $1(50)$ & $0(0)$ & 0.386 \\
\hline $\begin{array}{l}\text { Positive history of faecal } \\
\text { withdrawal }\end{array}$ & $4(26.7)$ & $8(44.4)$ & 0.29 & $0(0)$ & $0(0)$ & - & $1(50)$ & $0(0)$ & 0.386 \\
\hline $\begin{array}{l}\text { Positive history of pain } \\
\text { during defecation }\end{array}$ & $2(13.3)$ & $6(33.3)$ & 0.182 & $0(0)$ & $0(0)$ & - & $0(0)$ & $0(0)$ & - \\
\hline $\begin{array}{l}\text { Positive history visible } \\
\text { blood on the stool }\end{array}$ & $0(0)$ & $2(11.1)$ & 0.183 & $0(0)$ & $0(0)$ & - & $1(50)$ & $0(0)$ & 0.386 \\
\end{tabular}

Table III. Frequency of constipation among families of cases compared to controls

\begin{tabular}{|c|c|c|c|}
\hline Relative & Case, $n(\%)$ & Control, $n(\%)$ & Value of $p$ \\
\hline Father & $10(27)$ & $11(29.7)$ & 0.796 \\
\hline Mother & $18(48.6)$ & $8(21.6)$ & 0.015 \\
\hline $1^{\text {st }}$ child & $6(40)$ & $10(55.6)$ & 0.373 \\
\hline $2^{\text {nd }}$ child & $1(25)$ & $0(0)$ & 0.285 \\
\hline $3^{\text {rd }}$ child & $1(50)$ & $0(0)$ & 0.386 \\
\hline Number of families with at least one child with constipation & $6(40)$ & $10(55.6)$ & 0.373 \\
\hline Number of families with at least one parent with constipation & $24(64.9)$ & $16(43.2)$ & 0.062 \\
\hline Total number of children with constipation & $8(38.1)$ & $10(43.5)$ & 0.717 \\
\hline Total number of parents with constipation & $28(37.8)$ & $19(25.7)$ & 0.112 \\
\hline Total number of subjects with constipation & $36(37.9)$ & $29(29.9)$ & 0.242 \\
\hline
\end{tabular}


Table IV. Vegetable and legumes consumption between families of cases versus families of controls

\begin{tabular}{|c|c|c|c|c|c|c|c|c|c|c|}
\hline \multirow[t]{2}{*}{ Relative } & & \multicolumn{2}{|c|}{ Daily } & \multicolumn{2}{|c|}{ Three times/week } & \multicolumn{2}{|c|}{ One time/week } & \multicolumn{2}{|c|}{ Rarely } & \multirow{2}{*}{$\begin{array}{l}\text { Value } \\
\text { of } p\end{array}$} \\
\hline & & $\begin{array}{l}\text { Case } \\
n(\%)\end{array}$ & $\begin{array}{c}\text { Control } \\
n(\%)\end{array}$ & $\begin{array}{l}\text { Case } \\
n(\%)\end{array}$ & $\begin{array}{c}\text { Control } \\
n(\%)\end{array}$ & $\begin{array}{l}\text { Case } \\
n(\%)\end{array}$ & $\begin{array}{c}\text { Control } \\
n(\%)\end{array}$ & $\begin{array}{l}\text { Case } \\
n(\%)\end{array}$ & $\begin{array}{c}\text { Control } \\
n(\%)\end{array}$ & \\
\hline \multirow[t]{2}{*}{ Father } & Vegetables & $4(10.8)$ & $9(24.3)$ & $14(37.8)$ & $17(45.9)$ & $14(37.8)$ & 7 (18.9) & $5(13.5)$ & $4(10.8)$ & 0.199 \\
\hline & Legumes & $2(5.4)$ & $2(5.4)$ & $13(35.1)$ & $16(43.2)$ & $14(37.8)$ & $12(32.4)$ & $8(21.6)$ & 7 (18.9) & 0.912 \\
\hline \multirow[t]{2}{*}{ Mother } & Vegetables & $6(16.2)$ & $10(27)$ & $11(29.7)$ & $18(48.6)$ & $11(29.7)$ & 7 (18.9) & $9(24.3)$ & $2(5.4)$ & 0.045 \\
\hline & Legumes & $2(5.4)$ & $3(8.1)$ & $12(32.4)$ & $17(45.9)$ & $15(40.5)$ & $12(32.4)$ & $8(21.6)$ & $5(13.5)$ & 0.554 \\
\hline \multirow[t]{2}{*}{$1^{\text {st }}$ child } & Vegetables & $1(7.7)$ & $1(5.6)$ & $4(30.8)$ & $9(50)$ & $4(30.8)$ & $3(16.7)$ & $4(30.8)$ & $5(27.8)$ & 0.704 \\
\hline & Legumes & $2(15.4)$ & $2(11.1)$ & $4(30.8)$ & $7(38.9)$ & $6(46.2)$ & $4(22.2)$ & $1(7.7)$ & $5(27.8)$ & 0.368 \\
\hline \multirow[t]{2}{*}{$2^{\text {nd }}$ child } & Vegetables & $0(0)$ & $1(25)$ & $0(0)$ & $3(75)$ & $2(50)$ & $0(0)$ & $2(50)$ & $0(0)$ & 0.046 \\
\hline & Legumes & $0(0)$ & $1(25)$ & $1(25)$ & $2(50)$ & $2(50)$ & $0(0)$ & $1(25)$ & $1(25)$ & 0.343 \\
\hline \multirow[t]{2}{*}{$3^{\text {rd }}$ child } & Vegetables & - & - & $0(0)$ & $1(100)$ & $1(100)$ & $0(0)$ & - & - & 0.157 \\
\hline & Legumes & - & $1(100)$ & - & - & $1(100)$ & - & - & - & 0.157 \\
\hline \multirow[t]{2}{*}{ Total } & Vegetables & $11(12)$ & 21 (21.6) & $29(31.5)$ & $48(49.5)$ & $32(34.8)$ & 17 (17.5) & $20(21.7)$ & 11 (11.3) & 0.002 \\
\hline & Legumes & $6(6.5)$ & $9(9.3)$ & $30(32.6)$ & $42(43.3)$ & $38(41.3)$ & 28 (28.9) & 18 (19.6) & 18 (18.6) & 0.178 \\
\hline
\end{tabular}

There was no significant difference between families of cases and controls in terms of legumes consumption (Table IV). There was no significant difference between families of cases and controls regarding physical activity (Table V).

\section{Discussion}

There was no difference between the two groups regarding the prevalence of constipation in families

Table V. Physical activity among families of cases and controls

\begin{tabular}{lccc} 
Relative & $\begin{array}{c}\text { Case } \\
n(\%)\end{array}$ & $\begin{array}{c}\text { Control } \\
n(\%)\end{array}$ & $\begin{array}{c}\text { Value } \\
\text { of } p\end{array}$ \\
\hline Father & $15(40.5)$ & $18(48.6)$ & 0.482 \\
\hline Mother & $7(18.9)$ & $10(27)$ & 0.407 \\
\hline $1^{\text {st }}$ Child & $8(53.3)$ & $11(61.1)$ & 0.653 \\
\hline $2^{\text {nd }}$ Child & $1(25)$ & $3(75)$ & 0.157 \\
\hline $3^{\text {rd }}$ Child & $0(0)$ & $1(100)$ & 0.083 \\
\hline $\begin{array}{l}\text { No. of families with at least } \\
\text { one athlete child }\end{array}$ & $8(53.3)$ & $11(61.1)$ & 0.653 \\
\hline $\begin{array}{l}\text { No. of families with at least } \\
\text { one athlete parent }\end{array}$ & $18(48.6)$ & $20(54.1)$ & 0.642 \\
\hline $\begin{array}{l}\text { All children are athletes } \\
\text { Total number of athlete } \\
\text { parents }\end{array}$ & $9(42.9)$ & $15(65.2)$ & 0.137 \\
\hline $\begin{array}{l}\text { Total number of athletes } \\
\text { 2(29.7) }\end{array}$ & $28(37.8)$ & 0.297 \\
\hline
\end{tabular}

of children except in their mothers. In the study by Ostwani et al. the prevalence of constipation in families of children with constipation was significantly higher than in the controls [5]. In previous studies, the frequency of constipation was significantly higher among families of children with constipation compared to normal children [6, 7]. Their findings suggested genetic or environmental factors, which may be present among the families of children with constipation. Previous studies were carried out in the USA. Diet, genetic background, and physical activity may play a role in the different findings between two countries. However, in the study by Borowitz et al., which was carried out in the USA, there were no significant differences between constipated children and normal children in terms of parents with history of constipation ( $30 \%$ vs. $40 \%, p=0.141$ ) or siblings ( $17 \%$ vs. $14 \%, p=0.15)$ with history of constipation [6]. This controversy should be elucidated in future research.

Of the 21 siblings in the case group, 8 (38.9\%) had constipation. Of the 23 siblings in the control group, $10(43.48 \%)$ had constipation. The frequency of constipation among siblings of children with constipation (17\%) and children without constipation (14\%) was higher than that seen in the study by Borowitz et al. [6].

The frequency of constipation among parents was $24.32 \%$ (18 of 74 ) and $25.67 \%$ (19 of 74 ) for the case and control groups, respectively. Rate of constipation was higher in the study by Borowitz et al., which was $30 \%$ for parents of constipated children and $40 \%$ for parents of normal children [6]. In the study by Ostwani 
et al. the frequency of constipation among parents of constipated children was $42 \%$ and for children without constipation it was $9 \%$. There was a significant difference in the Ostwani et al. study [5].

This high frequency of constipation in our study may play a role in the insignificant findings with our sample size. In addition, the correct prevalence of constipation in our country remained unclear.

We included 37 families of children with constipation and 37 families of children without constipation. But in the study by Ostwani et al., a total of 112 children and their families were included [5]. However, genetic background and nutritional factors may also be important.

Vegetable consumption was significantly higher in families of controls compared to families of cases. Other studies support the beneficial effect of vegetable consumption on constipation [8].

There was no significant difference between the two groups regarding physical activity. Other studies showed a protective effect of exercise on constipation in adults [9]. In our study there was no significant difference between the two groups of families regarding prevalence of constipation, and this may be due to similarity in physical activity.

The place of sample collection in our study was the specialised paediatric gastroenterology clinic of the university. But in the study by Ostwani et al., samples were collected from different clinics [5]. This difference may explain the difference between the two studies. Several factors such as ethnicity, life style, weather, and nutrition may play role in constipation in families. Another prospective study with more samples is recommended for elucidation of familial clustering of constipation, especially the correlation between constipation of mothers and children in our country.

Due to the high frequency of constipation in our study, another study with more samples is recommended. We did not have reliable information about the quality of water in terms of mineral elements that are present with varying degree in water.

\section{Conclusions}

The frequency of constipation among mothers was significantly higher in the case group compared to the control group. Another study is recommended in a larger population for evaluation of genetic background, diet, physical activity, and familial clustering among mothers of children with constipation.

\section{Acknowledgments}

Data was used in this paper was from general physician thesis of Dr. Elahe Rajaei (NO. 89/2141); and financial support was provided by research affairs of Shiraz University of Medical Sciences.

\section{Conflict of interest}

The authors declare no conflict of interest.

\section{References}

1. Higgins PD, Johanson JF. Epidemiology of constipation in North America: a systematic review. Am J Gastroenterol 2004; 99 : 750-9.

2. Taitz L, Wales J, Urwin O, et al. Factors associated with outcome in management of defecation disorders. Arch Dis Child 1986; 61: 472-7.

3. Kalantar JS, Locke GR, Zinsmeister AR, et al. Familial aggregation of irritable bowel syndrome: a prospective study. Gut 2003; 52: 1703-7.

4. Chan AO, Hui WM, Lam KF, et al. Familial aggregation in constipated subjects in a tertiary referral center. Am J Gastroenterol 2007; 102: 149-52.

5. Ostwani W, Dolan J, Elitsur Y. Familial clustering of habitual constipation: a prospective study in children from West Virginia. J Pediatr Gastroenterol Nutr 2010; 50: 287-9.

6. Borowitz SM, Cox DJ, Tam A, et al. Precipitants of constipation during early childhood. J Am Board Fam Pract 2003; 16: 213-8.

7. Hyman PE, Milla PJ, Benninga MA, et al. Childhood functional gastrointestinal disorders: neonate/toddler. Gastroenterology 2006; 130: 1519-26.

8. Lee WT, Ip KS, Chan JS, et al. Increased prevalence of constipation in pre-school children is attributable to under-consumption of plant foods: a community-based study. J Paediatr Child Health 2008; 44: 170-5.

9. De Schryver AM, Keulemans YC, Peters HP, et al. Effects of regular physical activity on defecation pattern in middle-aged patients complaining of chronic constipation. Scand J Gastroenterol 2005; 40: 422-9.

Received: 11.07 .2014

Accepted: 1.10.2014 